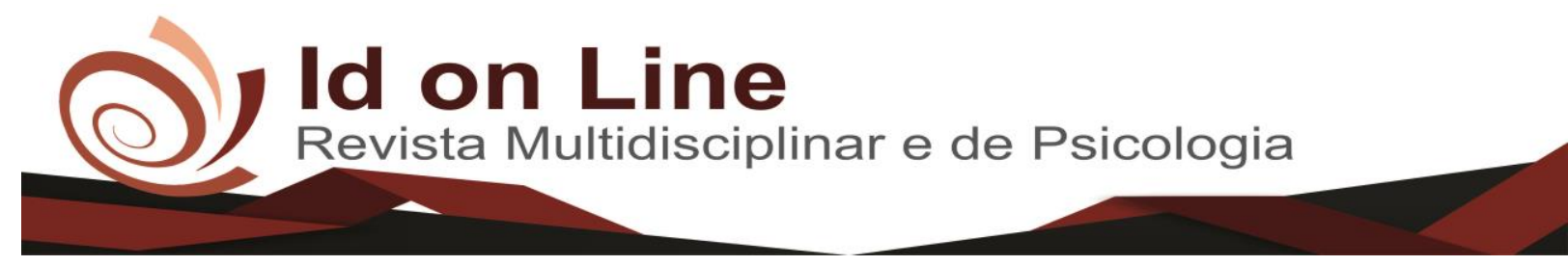

Artigo de Revisão

\title{
Acupuntura como Tratamento do Rejuvenescimento Facial: Uma Revisão Literária
}

\author{
Lana Rita de Oliveira Lima Santos ${ }^{1}$;Larissa de Oliveira Lima Santos Nascimento ${ }^{2}$; Josy Quélvia Alves Brito ${ }^{3}$
}

\begin{abstract}
Resumo: O envelhecimento da pele é um fenômeno fisiológico causado pela diminuição do colágeno, da elastina e das fibras que afetam os tecidos do corpo, que vão perdendo sua elasticidade natural. Este estudo tem como objetivo analisar as contribuições da acupuntura como tratamento rejuvenescedor facial. Trata-se de uma revisão bibliográfica baseada na literatura especializada através de consulta a artigos científicos e literaturas específicas. Os estudos encontrados apontaram que a acupuntura estética facial é um método que auxilia na redução de rugas, além de oferecer prevenção no processo de envelhecimento, melhorando a estrutura da pele, renovando o extrato córneo e estimulando a circulação local. Entre os efeitos mais específicos da acupuntura no tratamento rejuvenescedor, há um aumento na síntese das fibras colágenas e elásticas, reduzindo rugas e flacidez. É esperado que os efeitos da acupuntura voltada para o rejuvenescimento durem em até cinco anos. O rejuvenescimento facial com acupuntura complementa à cirurgia plástica estética como uma alternativa para outros procedimentos.
\end{abstract}

Palavras-chave: acupuntura, rugas, envelhecimento.

\section{Acupuncture as a Treatment for Facial Rejuvenation: A Literary Review}

\begin{abstract}
The aging of the skin is a physiological phenomenon caused by the gradual loss of collagen, elastin and fibers that affect the tissues of the body, causing it to lose its natural elasticity. This study aims to analyze the contributions of acupuncture as a facial rejuvenating treatment. This is a bibliographic review based on specialized literature through consultation of scientific articles and specific literatures. The studies found that facial cosmetic acupuncture is a method that helps in reducing wrinkles, in addition to offering prevention in the aging process, improving the structure of the skin, renewing the stratum corneum and stimulating the local circulation. Among more specific effects of acupuncture in rejuvenating treatments, there is an increase in the synthesis of collagen and elastic fibers, reducing wrinkles and sagging. It is expected that the effects of acupuncture on rejuvenation will last up to five years. Facial rejuvenation with acupuncture complements plastic surgery as an alternative to other procedures.
\end{abstract}

Keywords: acupuncture, wrinkles, aging.

\footnotetext{
${ }^{1}$ Graduanda em Estética e Cosmética pela Faculdade Independente do Nordeste - FAINOR

${ }^{2}$ Mestre em fitotecnia pela Universidade Estadual do Sudoeste da Bahia - UESB

${ }^{3}$ Professora orientadora e docente da Faculdade Independente do Nordeste - FAINOR 


\section{Introdução}

O processo de envelhecimento fisiológico é gradual e irreversível, podendo ser acelerado pela exposição solar, estilo de vida, meio ambiente, e característica individual de cada pessoa. Além disso, a herança genética e condições emocionais podem variar com a idade do indivíduo. Fatores externos, principalmente exposição solar causam degeneração das fibras de colágeno e elastina, e as microagressões mecânicas e de temperatura (calor, frio, umidade, secura, vento) também contribuem para esse processo (NAKANO; YAMAMURA, 2010).

Recursos simples podem ser utilizados, melhorando o aspecto geral da pele, seus riscos e gastos desnecessários. Dentre os recursos utilizados na área estética, a acupuntura destaca-se por ser uma técnica antiga e sem efeitos colaterais, harmonizando o indivíduo como um todo (GUIRRO; GUIRRO, 2002).

A prática de acupuntura data mais de cinco mil anos, e apenas recentemente ganhou espaço e reconhecimento. Ela utiliza de um conjunto de conhecimentos teóricos e práticos da Medicina Tradicional Chinesa, que visa o equilíbrio do organismo e consequentemente a cura de doenças por meio de agulhas, moxas e outras técnicas. O uso da acupuntura na área da estética está em grande expansão e a sua intervenção além de ser bastante sutil promove um equilíbrio energético, emocional e orgânico que naturalmente se manifesta no exterior do indivíduo, gerando felicidade, paz interior e satisfação pessoal (WEN, 2006).

Os músculos sempre movimentam para expressar emoções ao longo da vida. A diminuição do uso de determinados grupos musculares, irá selecionar quais tipos de rugas de expressão irão surgir. Por esse motivo, para um tratamento facial com acupuntura é importante a harmonização desses músculos. Observando o paciente como um todo é difícil definir quais os músculos acometidos, então na maioria das vezes depara-se com várias combinações de linhas de expressão na face. Além disso, observa-se que no envelhecimento cutâneo a pele não acompanha o processo de contração muscular, pois apresenta mais flacidez (FERNANDES, 2014).

Apesar da acupuntura ser uma ciência bastante antiga, continua sendo um campo aberto à pesquisa e novos conhecimentos. Neste sentido, aqueles que a praticam devem sensibilizarse da sua importância e estudar com profundidade outras alternativas para seu uso. Para além da mudança interna, a acupuntura facial consegue atingir resultados significativos deixando as rugas e linhas de expressão mais superficiais menos visíveis. Além disso, auxilia na produção 
de colágeno que é mantido pelo correto funcionamento do organismo, demonstrando o quão amplo é sua atuação (WEN, 2006). Nesta perspectiva, o presente estudo tem por objetivo analisar as contribuições da acupuntura como tratamento rejuvenescedor facial.

\section{Metodologia}

Este estudo tratou-se de uma revisão de literatura, realizada entre agosto e novembro de 2017, e segundo Marconi e Lakatos (2003), são um levantamento de toda a bibliografia já publicada, em forma de livros, revistas, publicações avulsas e impresso escrita.

As bases de pesquisa utilizadas para a busca de artigos foram Bireme, Google acadêmico, Scielo e em livros da biblioteca da Faculdade Independente do Nordeste - Fainor. Foram analisados 20 artigos que atenderam aos critérios de inclusão e exclusão definidos neste estudo.

Os critérios de inclusão foram: artigos nas línguas portuguesas e inglesa do período de 1990 a 2015. Os critérios de exclusão foram: artigos com mais de 20 anos de publicados. Para proceder à escolha dos artigos após a aplicação dos critérios de inclusão e exclusão foram: análise dos resumos e na presença de palavras-chave como acupuntura e envelhecimento.

\section{Resultados e Discussão}

A partir dos dados obtidos foi possível avaliar o uso da acupuntura no tratamento do envelhecimento cutâneo. Dessa forma, essa técnica possibilita a redução de rugas e marcas de expressão, contribuindo para elasticidade, circulação e tônus da pele. Seguem apresentados na tabela 1 os artigos utilizados e analisados para a construção da revisão de literatura do presente artigo. 
Tabela 1 Distribuição das fontes que avaliaram a técnica da acupuntura no rejuvenescimento facial.

\begin{tabular}{|c|c|c|c|c|}
\hline Autor & Tema & Objetivo & Metodologia & Ano \\
\hline $\begin{array}{l}\text { BARRET, John } \\
\text { B. }\end{array}$ & $\begin{array}{l}\text { Acupuntura } \mathrm{e} \\
\text { rejuvenescimento } \\
\text { facial }\end{array}$ & $\begin{array}{l}\text { Estudar a diminuição } \\
\text { de rugas e edema facial }\end{array}$ & Estudo de caso & 2005 \\
\hline $\begin{array}{l}\text { BERNARDO- } \\
\text { FILHO, Mario } \\
\text { et al. }\end{array}$ & $\begin{array}{l}\text { Técnicas } \\
\text { relacionadas à } \\
\text { medicina } \\
\text { tradicional chinesa } \\
\text { no tratamento da } \\
\text { acne vulgar }\end{array}$ & $\begin{array}{l}\text { Tratamento das } \\
\text { afecções } \\
\text { dermatológicas } \\
\text { denominadas de acne } \\
\text { vulgar }\end{array}$ & $\begin{array}{l}\text { Revisão } \\
\text { literatura }\end{array}$ & 2008 \\
\hline $\begin{array}{l}\text { BOCK, } \\
\text { Vanessa; } \\
\text { NORONHA, } \\
\text { Alessandra } \\
\text { Ferreira de. }\end{array}$ & 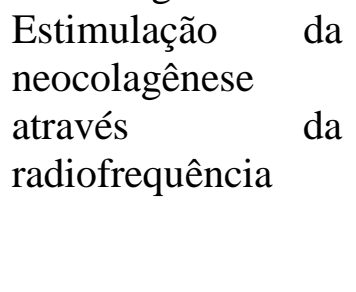 & $\begin{array}{l}\text { Analisar se a } \\
\text { radiofrequência } \\
\text { promove a estimulação } \\
\text { do colágeno } \\
\text { amenizando os sinais } \\
\text { do envelhecimento }\end{array}$ & $\begin{array}{l}\text { Revisão } \\
\text { literatura }\end{array}$ & 2013 \\
\hline $\begin{array}{l}\text { CHEN, Chung- } \\
\text { Jen; YU, Hsin- } \\
\text { Su. }\end{array}$ & $\begin{array}{l}\text { Acupuntura, } \\
\text { eletroestimulação e } \\
\text { reflexoterapia em } \\
\text { dermatologia }\end{array}$ & $\begin{array}{l}\text { Estudo de tratamentos } \\
\text { de doenças dérmicos } \\
\text { refratárias }\end{array}$ & $\begin{array}{l}\text { Revisão } \\
\text { literatura }\end{array}$ & 2003 \\
\hline $\begin{array}{l}\text { FERNADES, } \\
\text { Fernando A. C. }\end{array}$ & $\begin{array}{l}\text { Acupuntura estética } \\
\text { e no pós-operatório } \\
\text { de cirurgia plástica. }\end{array}$ & $\begin{array}{l}\text { A proposta é congregar } \\
\text { diversas possibilidades } \\
\text { de tratamento com a } \\
\text { MTC, de acordo com a } \\
\text { necessidade de cada } \\
\text { caso. }\end{array}$ & Livro & 2014 \\
\hline $\begin{array}{l}\text { FERNADES, } \\
\text { Fernando A. C. }\end{array}$ & $\begin{array}{l}\text { Acupuntura } \\
\text { estética: prática e } \\
\text { objetiva }\end{array}$ & $\begin{array}{l}\text { Visa tornar prático e } \\
\text { objetivo o uso de } \\
\text { protocolos, utilizando } \\
\text { novos e antigos } \\
\text { recursos da medicina } \\
\text { oriental }\end{array}$ & Livro & 2015 \\
\hline $\begin{array}{l}\text { FORNAZIERI, } \\
\text { Luiz Carlos }\end{array}$ & $\begin{array}{l}\text { Tratado de } \\
\text { acupuntura estética }\end{array}$ & $\begin{array}{lr}\text { Experiência didática e } \\
\text { clínica, } & \text { com } \\
\text { informações } & \\
\text { fundamentais } & \text { ao } \\
\text { atendimento } & \text { da } \\
\text { acupuntura estética }\end{array}$ & Livro & 2007 \\
\hline $\begin{array}{l}\text { GUIRRO, } \\
\text { Elaine; } \\
\text { GUIRRO, } \\
\text { Rinaldo }\end{array}$ & $\begin{array}{l}\text { Fisioterapia } \\
\text { dermato-funcional: } \\
\text { fundamentos, } \\
\text { recursos e } \\
\text { patologias }\end{array}$ & $\begin{array}{l}\text { Contribuir para a } \\
\text { formação e atualização } \\
\text { de novos profissionais. }\end{array}$ & Livro & 2002 \\
\hline $\begin{array}{l}\text { HIRATA, Lilian } \\
\text { Lúcio et al. }\end{array}$ & $\begin{array}{l}\text { Radicais Livres e o } \\
\text { Envelhecimento } \\
\text { Cutâneo }\end{array}$ & $\begin{array}{l}\text { Desenvolver pesquisas } \\
\text { que visem a prevenção }\end{array}$ & $\begin{array}{l}\text { Revisão } \\
\text { literatura }\end{array}$ & 2004 \\
\hline
\end{tabular}




\section{do envelhecimento}

precoce cutâneo

MENDONÇA, As principais Abordar as dermatoses

Rosimeri da alterações que mais acometem

Revisão de 2011

Silva Castanho; dermatológicas em pacientes obesos e seu

RODRIGUES, pacientes obesos tratamento

Geruza Baima

de Oliveira.

\begin{tabular}{|c|c|c|c|c|c|}
\hline $\begin{array}{l}\text { MENOITA, } \\
\text { Elsa et al. }\end{array}$ & $\begin{array}{l}\text { A pele na pessoa } \\
\text { idosa }\end{array}$ & $\begin{array}{l}\text { Evidenciar a } \\
\text { necessidade de } \\
\text { cuidados específicos } \\
\text { para a pele do idoso }\end{array}$ & $\begin{array}{l}\text { Revisão } \\
\text { literatura }\end{array}$ & de & 2013 \\
\hline $\begin{array}{l}\text { MONTAGNER, } \\
\text { Suelen; } \\
\text { COSTA, } \\
\text { Adilson. }\end{array}$ & $\begin{array}{l}\text { Bases } \\
\text { biomoleculares do } \\
\text { fotoenvelhecimento }\end{array}$ & $\begin{array}{l}\text { Pesquisas } \\
\text { desenvolvidas com } \\
\text { intuito de combater o } \\
\text { fotoenvelhecimento }\end{array}$ & $\begin{array}{l}\text { Revisão } \\
\text { literatura }\end{array}$ & de & 2009 \\
\hline $\begin{array}{l}\text { NAKANO, } \\
\text { Maria Assunta } \\
\text { Y.; } \\
\text { YAMAMURA, } \\
\text { Ysao }\end{array}$ & $\begin{array}{lr}\text { Livro dourado } & \text { da } \\
\text { acupuntura } & \text { em } \\
\text { dermatologia } & \\
\text { estética } & \end{array}$ & $\begin{array}{l}\text { Abrange os princípios } \\
\text { básicos da medicina } \\
\text { tradicional chinesa }\end{array}$ & Livro & & 2010 \\
\hline $\begin{array}{l}\text { PALMEIRA, } \\
\text { Guido. }\end{array}$ & $\begin{array}{l}\text { A acupuntura no } \\
\text { ocidente }\end{array}$ & $\begin{array}{l}\text { Reconhecimento da } \\
\text { eficácia da acupuntura }\end{array}$ & $\begin{array}{l}\text { Revisão } \\
\text { literatura }\end{array}$ & de & 1990 \\
\hline $\begin{array}{l}\text { RÖCKEN, } \\
\text { Martin et al. }\end{array}$ & $\begin{array}{l}\text { Dermatologia texto } \\
\text { e atlas }\end{array}$ & $\begin{array}{lr}\text { Avanços } & \text { na } \\
\text { compreensão } & \text { em } \\
\text { diagnósticos } & \\
\text { dermatológicos } & \end{array}$ & Livro & & 2013 \\
\hline $\begin{array}{l}\text { SILVA, Alex } \\
\text { Sandro Tavares } \\
\text { da. }\end{array}$ & $\begin{array}{l}\text { Acupuntura sem } \\
\text { segredos: } \\
\text { tratamento natural, } \\
\text { milenar e científico }\end{array}$ & $\begin{array}{l}\text { Prevenção, tratamento } \\
\text { e cura de patologias }\end{array}$ & $\begin{array}{l}\text { Revisão } \\
\text { literatura }\end{array}$ & de & 2007 \\
\hline $\begin{array}{l}\text { SILVA FILHO, } \\
\text { Reginaldo } \\
\text { Carvalho da; } \\
\text { PRADO, } \\
\text { Gilmar } \\
\text { Fernandes do }\end{array}$ & $\begin{array}{ll}\text { Os efeitos } & \text { da } \\
\text { acupuntura } & \text { no } \\
\text { tratamento } & \text { da } \\
\text { insônia } & \end{array}$ & $\begin{array}{l}\text { Identificar } \quad \text { estudos } \\
\text { clínicos de valor } \\
\text { científico sobre os } \\
\text { efeitos da acupuntura } \\
\text { no tratamento da } \\
\text { insônia }\end{array}$ & $\begin{array}{l}\text { Revisão } \\
\text { literatura }\end{array}$ & de & 2007 \\
\hline $\begin{array}{l}\text { SOARES, } \\
\text { Margarida et al. }\end{array}$ & $\begin{array}{l}\text { Permeação cutânea: } \\
\text { desafios e } \\
\text { oportunidades }\end{array}$ & $\begin{array}{l}\text { Revisão de estratégias } \\
\text { desenvolvidas com o } \\
\text { objetivo de aumentar a } \\
\text { permeação } \\
\text { fármacos de }\end{array}$ & $\begin{array}{l}\text { Revisão } \\
\text { literatura }\end{array}$ & de & 2015 \\
\hline $\begin{array}{l}\text { SOUZA, Soraya } \\
\text { L. G. et al. }\end{array}$ & $\begin{array}{l}\text { Recursos } \\
\text { fisioterapêuticos } \\
\text { utilizados no } \\
\text { tratamento do } \\
\text { envelhecimento } \\
\text { facial }\end{array}$ & $\begin{array}{l}\text { Instruir } \\
\text { profissionais } \\
\text { fisioterapeutas a } \\
\text { respeito da terapêutica } \\
\text { utilizada para } \\
\text { atenuação desses sinais }\end{array}$ & $\begin{array}{l}\text { Revisão } \\
\text { literatura }\end{array}$ & de & 2007 \\
\hline
\end{tabular}




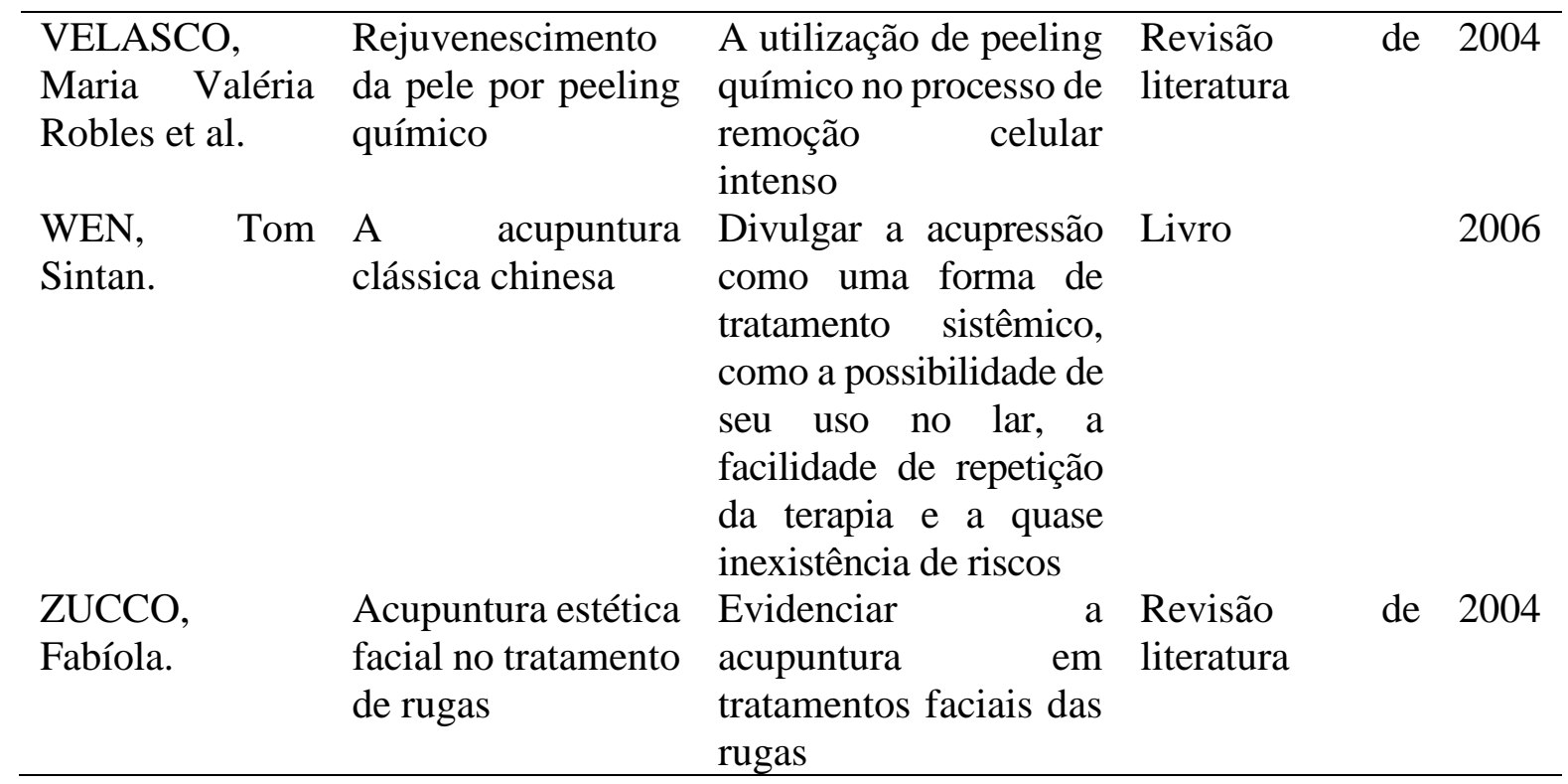

Fonte: dados da pesquisa.

\section{A pele}

A pele representa $12 \%$ do peso seco do corpo. Considerado o maior órgão corporal, é formada por duas camadas distintas: epiderme, derme e hipoderme. A epiderme é formada por tecido epitelial estratificado, camada mais superficial, composta por queratinócitos, melanócitos, células com capacidade de sintetizar melanina e proteção contra os raios UV, células de Langerhas, apresentadora de antígenos da pele, células de Merkel integrados ao sistema nervoso e células dendríticas. Além disso, não possui circulação sanguínea e linfática (MENDONÇA; RODRIGUES, 2011).

Diferente da epiderme, a derme, camada mais consistente da pele e vascularizada é constituída por vários tipos de células, nervos, vasos sanguíneos e linfáticos distribuídos numa vasta rede de tecido conjuntivo denso, composta por seus principais componentes, feixes de fibras colágenas e elásticas (SOARES et al., 2015).

A hipoderme é uma camada de tecido conjuntivo frouxo que conecta a derme à fáscia dos músculos subjacentes. Nela situam-se algumas fibras elásticas e reticulares, bem como muitas fibras colágenas, sendo suprida por vasos sanguíneos, vasos linfáticos e nervos e ainda contém glândulas especializadas e órgãos do sentido (MENDONÇA; RODRIGUES, 2011). 
Esse órgão oferece proteção contra um amplo espectro de agentes nocivos como a radiação UV, impactos térmicos e mecânicos, microrganismos patogênicos, grandes e pequenas substâncias moleculares, incluindo alérgenos. Desempenha um papel decisivo na manutenção das funções vitais do corpo, como o controle do equilíbrio hídrico e térmico (ROCKEN et al., 2013).

A pele é considerada um dos órgãos que mais sofre mudanças à medida que o tempo avança. Manter a integridade cutânea é de grande importância, para que o organismo venha a se defender de possíveis mudanças ou alterações no qual os indivíduos estão expostos. Com o passar da idade, há uma diminuição da espessura epiderme-derme, redução da elastina, e das glândulas sebáceas e sudoríparas e há um comprometimento na resposta imunológica, e na fragilidade dos vasos sanguíneos (MENOITA et al., 2013).

\section{Envelhecimento Cutâneo}

Envelhecimento é um fenômeno fisiológico que afeta os tecidos do corpo em geral, e na pele prejudica principalmente o colágeno, componente fundamental do tecido conjuntivo, e a elastina, componente do mesmo tecido que vai perdendo sua elasticidade natural, devido à diminuição nos números de fibras. Além disso, ocorre também uma redução das glicosaminoglicanas, associada à redução de água, que por sua vez diminui adesão, migração, desenvolvimento e diferenciação celular. (BOCK; NORONHA, 2013)

O processo de envelhecimento ocorre tanto por fatores externos (extrínsecos) quanto internos (intrínsecos). Neste último, a pele se manifesta tanto por fatores genéticos e naturais associados às mudanças hormonais, como a menopausa. Extrinsecamente, a pele sofre influências ambientais, como poluição, exposição aos raios UV, vento, umidade, doenças dermatológicas, e estilo de vida como, álcool, fumo e alimentação (VELASCO et al., 2004).

No envelhecimento intrínseco, acontece uma deterioração dos sistemas orgânicos, envelhecimento natural que atinge todos os seres humanos e é teoricamente inevitável. Ocorre modificações no aspecto, estrutura, e funções da pele onde as fibras colágenas tornam-se grossas e as fibras elásticas perdem boa parte da sua função. Há uma alteração na densidade dos melanócitos, favorecendo o aparecimento de manchas hiperpigmentares, como esfelides, lentigos, leucodermias, entre outras alterações (MENOITA et al., 2013). 
A pele se torna mais fina, seca, pálida e aparecem as rugas. Há uma sensibilidade no sistema circulatório, fazendo com que a pele perca sua firmeza, dando uma aparência irregular. Há também uma diminuição na atividade dos fibroblastos e a síntese do colágeno se torna mais lenta, o qual sofre ligação cruzada pela glicose, no fenômeno de glicação (HIRATA et al., 2004).

O envelhecimento provoca alterações celulares, diminuindo a capacidade dos órgãos de desempenhar suas funções naturais causando enfermidade e morte. Trata-se das mudanças progressivas do organismo em resposta adaptativa às mudanças ambientais (MONTAGNER; COSTA, 2009).

\section{A acupuntura}

A acupuntura é um procedimento milenar e integra os procedimentos da medicina tradicional chinesa (MTC), e significa puncturar algumas partes do corpo em pontos específicos por agulhas. Com o passar do tempo a técnica passou a ser constituída pela acupuntura original, e outros métodos, como moxabustão (aplicação de calor), a ventosa, a acupressão (pressões negativas e positivas), técnicas de auriculoterapia (sementes aplicadas no pavilhão auricular) (BERNARDO-FILHO et al., 2008).

A Medicina Tradicional Chinesa possui uma visão muito particular do corpo humano, de como ele relaciona com o meio externo e consigo mesmo. As interpretações das doenças e suas causas são principalmente por fatores externos e internos, fatores esses que impedem os órgãos e víceras (Zang Fu) a ter um funcionamento adequado, o Qi e o Xue (sangue), circulem pelo corpo e principalmente pelos canais colaterais (Jing Luo), onde se localizam os pontos de acupuntura (SILVA FILHO; PRADO, 2007).

A acupuntura é uma terapia perfeita que atua e integra um padrão de funcionamento do ser vivo a nível biológico, psicológico e comportamental. Quando bem indicada, possui propriedades terapêuticas, preventivas, segura, rápida e eficaz, com efeito duradouro e de baixo custo financeiro (SILVA, 2007).

Dessa forma, é uma das técnicas terapêuticas que faz parte da sabedoria e procedimentos da Medicina Chinesa. Além das agulhas, a medicina tradicional chinesa utiliza ervas, exercícios físicos, dietas alimentares, massagens, e prescreve normas de higiene que servem para 
compreender, classificar e lidar com as coisas do mundo, natureza, espaço e tempo (PALMEIRA, 1990).

De acordo com os chineses, ao que se referem às rugas da face, os danos da pele causados pela idade dependem de alterações dos rins, enquanto os problemas da derme dependem do baço pâncreas, as da epiderme ao pulmão, as do tônus da musculatura da face ao fígado e as das expressões faciais ao coração. Problemas emocionais também influenciam a pele, pois todos os mediadores químicos encontrados no sistema nervoso central também se encontram em outros órgãos do corpo, como a pele, o que permite uma interação da mente com todo o resto do corpo (NAKANO; YAMAMURA, 2010).

A acupuntura estética facial é um método que auxilia na redução de rugas, além de oferecer prevenção no processo de envelhecimento, melhorando a estrutura da pele, renovando o extrato córneo e estimulando a circulação local (ZUCCO, 2004).

\section{Pontos de acupuntura (acupontos)}

Os pontos de acupuntura estão em uma região da pele onde se concentra um grande número de terminações nervosas sensoriais, estão intimamente ligados com nervos, vasos sanguíneos, tendões, periósteos e cápsulas articulares.

Na tabela 2 estão indicadas possíveis ações de acupontos empregados em tratamentos estéticos para rejuvenescimento facial.

Tabela 2 Possíveis ações de acupontos empregados em tratamentos estéticos para rejuvenescimento facial.

\begin{tabular}{ll}
\hline Acupontos & \multicolumn{1}{c}{ Ações } \\
\hline IG-19 (Heliao) & Responsável pela ruga peribucal superior. \\
IG-20 (Yingxiang) & Responsável pela ruga paranasal. \\
VG-26 (Renzhong ou Shuigou) & Comanda o lábio superior e o músculo \\
& orbicular oral superior. \\
VC-24 (Chengjiang) & Comando sobre o músculo orbicular oral \\
& inferior e sobre o lábio inferior.
\end{tabular}


M-CP-18 (Jiachengjiang)

M-CP-6 (Yиуао)

M-CP-8 (Qiuhou)

E-2 (Sibai)

VB-1 (Tongziliao)

TA-23 (Shizukong)

B-2 (Zanzhu)

E-3 (Juliao)

E-7 (Xiaguan)
Ação sobre o músculo depressor do ângulo bucal.

Responsável pela formação da ruga vertical entre sobrancelhas.

Comando sobre o músculo orbicular do olho responsável pela formação de ruga periocular externa superior.

Comando sobre o músculo orbicular do olho, na sua porção inferior.

Comando sobre o músculo orbicular do olho, na sua porção lateral.

Comando sobre o músculo frontal ou sobre o músculo orbicular ocular.

Comando sobre o músculo corrugador.

Comando sobre o músculo elevador do lábio superior e sobre a região da pálpebra inferior. Comando sobre os músculos do sorriso e nervo facial.

Fonte: Nakano e Yamamura, 2010.

O uso das técnicas de acupuntura está referente com o fato desses acupontos terem relação com regiões de acesso no trajeto externo dos canais energéticos dos órgãos e vísceras, conhecidos como Zang Fu e oito meridianos chamados de maravilhosos, sendo que desses últimos, o Governador e o da Concepção apresentam seus próprios acupontos (BERNARDOFILHO et al., 2008).

Especialistas em acupuntura clássica colocam uma atenção relevante na energia do corpo do indivíduo, e indicam diferentes formas de alcançar um equilíbrio energético. Em casos de excesso de energia, é indicada estimulação forte para diminuir a energia corporal (conhecida como sedante). No caso de deficiência energética, a estimulação suave é escolhida para dar intensidade à energia do corpo, conhecida como tonificação (CHEN; YU, 2003).

Segundo os autores acima citados, pelo menos três componentes principais estão envolvidos na estimulação da acupuntura: o eixo hipotálamo adrenal hipofisário, o sistema 
nervoso autônomo e o fator neurotrófico derivado do cérebro. A eletroacupuntura pode causar liberação de endorfina e corticotrofinano sangue periférico. Comprovou-se que o sistema límbico-hipotálamo é ativado nitidamente pela acupuntura manual com agulhas.

As técnicas para tratamento do envelhecimento facial, como o botox, lift, preenchimento, peeling, vem avançando bastante, com opções de redução de linhas de expressão e rugas, melhorando a aparência da pele (SOUZA et al., 2007).

\section{Acupuntura e rejuvenescimento}

$\mathrm{Na}$ medicina oriental tradicional, o rejuvenescimento facial é adquirido através da aplicação de agulhas de acupuntura em diferentes pontos ao longo dos canais indicados para atingir efeitos de tonificação ou sedação. Segundo Barret (2005), os proveitos do tratamento incluem a retirada de algumas rugas, diminuindo edema, acne, melhorando o tônus muscular facial, diminuição dos poros, e da flacidez ao redor dos olhos, bochechas, queixo e pescoço. $\mathrm{O}$ rejuvenescimento facial com acupuntura complementa à cirurgia plástica estética como uma alternativa para outros procedimentos.

Com o passar do tempo, a acupuntura passou a incluir vários métodos relacionados com moxabustão (aplicação de calor), ventosa e acupressão, que são pressões negativas e positivas, respectivamente, aplicados em regiões específicas do corpo. Nas técnicas de auriculoterapia ou acupuntura auricular, são realizadas pressões com auxílio de sementes aplicadas no pavilhão auricular (BERNARDO-FILHO et al., 2008).

A Medicina Tradicional Chinesa é um tratamento holístico, que visa restaurar a saúde e o bem-estar geral do indivíduo, onde o rosto reflete os órgãos internos. Uma pessoa com a circulação saudável, digestão e padrões de sono, se sente e aparenta mais jovem. É esperado que os efeitos da acupuntura voltada para o rejuvenescimento durem em até cinco anos, com os seguintes resultados: eliminação e diminuição do comprimento e profundidade das rugas, diminuição do edema facial, aumento do tônus muscular, aparência mais viva dos olhos, diminuição da flacidez ao redor dos olhos, bochechas, queixo e pescoço (BARRET, 2005).

Na MTC é de grande importância o diagnóstico através da visualização, no qual podem ser encontradas diversas situações que demandam terapêuticas diferenciadas. Contudo, na 
diagnose visual serão observadas características da face, rugas, inchaços, descamações, irritações e manchas, conforme aponta o tabela 3 (FORNAZIERI, 2007).

\section{Vantagens e desvantagens da acupuntura}

A acupuntura possui inúmeras vantagens, comparadas a outras técnicas. É praticamente indolor, o custo é baixo, sem efeitos colaterais, resultados rápidos, reestabelecendo o equilíbrio energético, tratando queixas secundárias e devolvendo a homeostase do organismo. A pequena desvantagem é o medo ocasionado pelas agulhas (FERNANDES, 2015).

Tabela 3 - Diagnose visual

\section{Pálpebras Inferiores}

Bolsas ou inchaços nesta região podem indicar acúmulo de líquidos ou rins sobrecarregados.

Demonstra as condições de distribuição de água e sais minerais no organismo.

\section{Rugas Verticais}

Rugas verticais na região frontal, ou sulcos entre as sobrancelhas indicam má função do Fígado ou da Vesícula Biliar, provocado por substâncias agressivas ou sobrecarga.

\section{Rugas Horizontais}

Rugas horizontais na região frontal indicam pessoas tensas e nervosas, provocados por excesso de trabalho mental, preocupações, ingestão de alimentos fermentativos (ex.pão branco).

\section{Sobrancelhas}

Sobrancelhas caídas sobre os olhos demonstram cansaço e indica redução da função das suprarrenais, o que diminui a resistência a situações de estresse.

Rugas Para-Oculares

As rugas para-oculares ou "pés-de-galinha" no canto externo dos olhos podem indicar excesso de toxinas e umidade no organismo.

\section{Lábio Superior}

Corresponde ao estômago, função gástrica e início do intestino, duodeno e jejuno.

Lábio superior rachado, com sulcos, aftas, inchaço, palidez, vermelhidão, indica problemas ligados ao intestino, duodeno e jejuno. 
Lábio Inferior

Corresponde ao Intestino Grosso. Pessoas com o lábio inferior espesso sofrem de intestino preso, flatulência, acúmulo de resíduos e cólicas.

Maçãs do Rosto

Revelam a saúde geral do organismo. Quando essa área está pálida, sem vida, reflete saúde deficiente e falta de oxigenação dos tecidos.

Ponta do Nariz

Corresponde ao coração e ao sistema cardiovascular. Coloração vermelha, dilatada ou levemente inchada, indica uma possível angina pectoris, pré-infarte e dilatação do coração. Pequenas veias e vasos dilatados nesta região alertam para problemas no coração.

Asas do Nariz

Essa região representa os pulmões. Pequenos vasos dilatados, inchaços e descamações indicam dilatações da árvore respiratória e inflamações do tecido bronquiolar pulmonar.

Queixo

A região do queixo e abaixo do lábio inferior revela condições funcionais especificas ou hereditárias. Refere-se a influência do aparelho genital, do sistema hormonal e do sistema simpático e parassimpático na personalidade, temperamento e bioenergética.

Sulcos

Sulcos profundos e precoces podem indicar excesso de alcoolismo, excessos sexuais, abusos alimentares, líquidos em excesso, drogas, vida noturna intensa, irritação do fígado, etc.

Fonte: FORNAZIERI, 2007.

\section{Conclusão}

A partir dos dados levantados para a elaboração deste artigo, pode-se observar que a acupuntura estética como tratamento facial, não só atua na atenuação das rugas, como também trabalha o indivíduo como um todo, normalizando o funcionamento dos sistemas e órgãos internos, os quais possuem influência direta na saúde da pele, suavizando linhas de expressão, tonificando músculos, melhorando a circulação e nutrição local, favorecendo uma melhora no aspecto geral da pele e retardando o envelhecimento precoce da mesma. No entanto, apesar de 
várias pesquisas realizadas, ainda há uma carência de estudos científicos comprovando sua verdadeira eficácia, sobretudo no ocidente.

\section{Referências}

BARRET, John B. Acupuncture and Facial Rejuvenation. Aesthetic Surgery Journal, v. 25, n. 4. 2005.

BERNARDO-FILHO, Mario et al. Técnicas relacionadas à medicina tradicional chinesa no tratamento de acne vulgar. Fisioterapia ser, v. 3, n. 4. 2008.

BOCK, Vanessa; NORONHA, Alessandra Ferreira de. Estimulação da neocolagênese através da radiofrequência. Revista Eletrônica Saúde e Ciência, v. 3, n. 2, p. 7-17. 2013.

CHEN, Chung-Jen; YU, Hsin-Su. Acupunture, electrostimulation, and reflex therapy in dermatology. Dermatologic Therapy, v. 16, p. 87-92. 2003.

FERNADES, Fernando A. C. Acupuntura estética e no pós-operatório de cirurgia plástica. 4 ed. São Paulo: Ícone, 2014.

FERNADES, Fernando A. C. Acupuntura estética: prática e objetiva. 2 ed. São Paulo: Ícone, 2015 .

FORNAZIERI, Luiz Carlos. Tratado de Acupuntura Estética. 1 ed. São Paulo: Ícone, 2007.

GUIRRO, Elaine; GUIRRO, Rinaldo. Fisioterapia dermato-funcional: fundamentos, recursos e patologias. 3 ed. São Paulo: Manole, 2002.

HIRATA, Lilian Lúcio et al. Radicais Livres e o Envelhecimento Cutâneo. Acta Farm. Bonaerense, v. 23, n. 3, p. 418-24. 2004.

LAKATOS, E. M.; MARCONI, M. A. Fundamentos da metodologia científica. Atlas, $5^{\mathrm{a}}$ ed, 2003.

MENDONÇA, Rosimeri da Silva Castanho; RODRIGUES, Geruza Baima de Oliveira. As principais alterações dermatológicas em pacientes obesos. ABCD Arq Bras Cir Dig, v. 24, n. 1, p. 68-73, 2011.

MENOITA, Elsa et al. A pele na pessoa idosa. Journal of Aging and Inovation, v. 2, p. 18-33. 2013.

MONTAGNER, Suelen; COSTA, Adilson. Bases biomoleculares do fotoenvelhecimento. An Bras Dermatol., v. 84, n. 3, p. 263-9, 2009. 
NAKANO, Maria Assunta Y.; YAMAMURA, Ysao. Livro dourado da acupuntura em dermatologia e estética. Center AO, $2^{\mathrm{a}}$ ed, 2010.

PALMEIRA, Guido. A acupuntura no Ocidente. Cadernos de Saúde Pública, RJ, v. 6, n. 2, p. 117-128. 1990.

RÖCKEN, Martin et al. Dermatologia texto e atlas. Artmed, 2013.

SILVA, Alex Sandro Tavares da. Acupuntura sem segredos: tratamento natural, milenar e científico. Psicologia Actual, n. 10, Lisboa, Portugal. 2007.

SILVA FILHO, Reginaldo Carvalho da; PRADO, Gilmar Fernandes do. Os efeitos da acupuntura no tratamento da insônia: revisão sistemática. Rev Neurocienc, v. 15, n. 3, p. 183$189,2007$.

SOARES, Margarida et al. Permeação cutânea: desafios e oportunidades. Rev Ciênc Farm Básica Apl., v. 36, n. 3, p. 337-348. 2015.

SOUZA, Soraya L. G. et al. Recursos Fisioterapêuticos utilizados no tratamento do envelhecimento facial. Revista Fafibe On Line, n.3. 2007.

VELASCO, Maria Valéria Robles et al. Rejuvenescimento da pele por peeling químico: enfoque no peeling de fenol, An bras Dermatol, Rio de Janeiro, v. 79, n. 1, p. 91-99. 2004.

WEN, Tom Sintan. A acupuntura clássica chinesa. 11 ed. São Paulo: Cultrix, 2006.

ZUCCO, Fabíola. Acupuntura Estética Facial no Tratamento de Rugas. World Gate Brasil Ltda., 2004. Disponível em: http://www.wgate.com.br/conteudo/ medicinaesaude/fisioterapia/variedades/acupuntura_rugas .htm Acesso em 10 de outubro de 2017.

\section{Como citar este artigo (Formato ABNT):}

SANTOS, Lana Rita de O. L.; NASCIMENTO, Larissa de O.L.S.; BRITO, Josy Q.A. Acupuntura como Tratamento do Rejuvenescimento Facial: Uma Revisão Literária. Id on Line Rev.Mult. Psic., 2018, vol.12, n.40, p.382-396. ISSN: 1981-1179.

Recebido: 06/04/2018

Aceito 12/04/2018 